\title{
Preface - Special Issue Dedicated to Professor Herbert Mayr
}

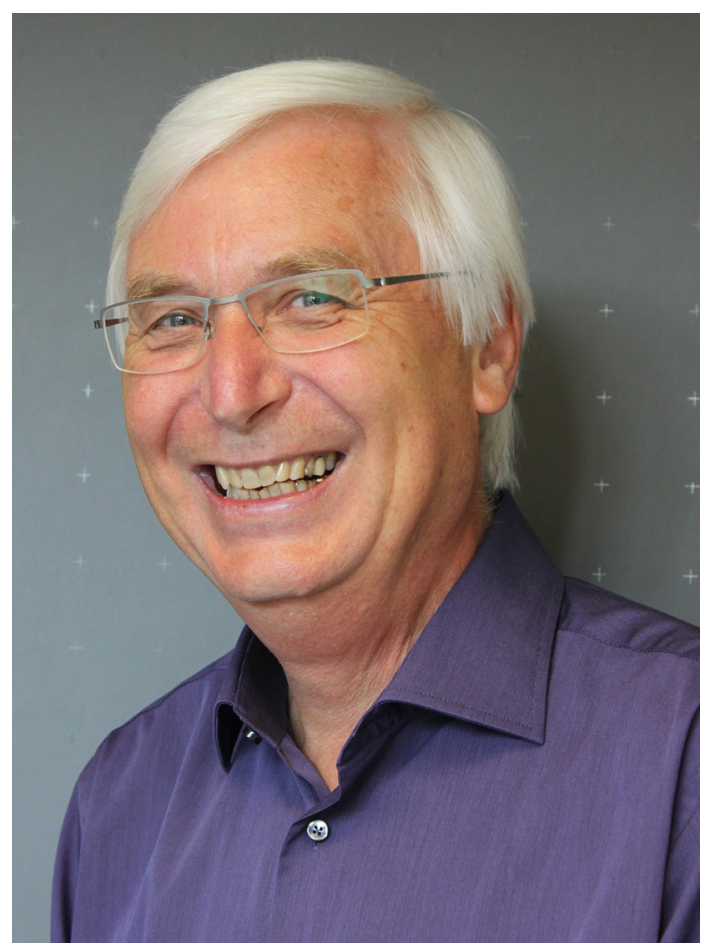

Dear Herbert,

It is an immense pleasure in the name of my colleagues at the Ludwig-Maximilians-Universität München and of all participants of the Symposium "Dynamics and Intermediates of Molecular Transformations" to initiate this Special Issue of SYNTHESIS dedicated to you on the occasion of your $70^{\text {th }}$ birthday.

You have studied chemistry at the Ludwig-MaximiliansUniversität in Munich and have obtained your Ph.D. at the same institution in 1974 under the guidance of Prof. Rolf Huisgen. The seven publications resulting from your Ph.D. on the mechanism of ketone cycloaddition and on the chemistry of cyclobutenone were all published long after you completed your postdoctoral stay at Case Western Reserve University (Cleveland) with Prof. George Olah (Nobel Prize Awardee in 1994). You mentioned in your Angewandte Chemie biographical sketch (Angew. Chem. Int. Ed. 2012, $51,34)$ how amazing it was to be able to obtain a postdoctoral fellowship from the DFG (Deutsche Forschungsgemeinschaft) at this time without any publication! You came back to Germany and achieved your Habilitation at the University of Erlangen-Nuremberg within four years as an associate of the laboratory of Prof. Paul von Ragué Schleyer. After having been Full Professor at the University of Lübeck, you moved to the University of Darmstadt (TU Darmstadt) in 1991 and to the Ludwig-Maximilians-Universität in 1996, where you continued your important studies on the kinetics of polar organic reactions which resulted in the development of your nucleophilicity and electrophilicity scales. Your work on the reference scales for the characterization of cationic electrophiles and neutral nucleophiles has changed organic chemistry. Often, my students or myself, we examine your reactivity scales in order to estimate if an unknown reaction may have a chance to succeed or not. You have also established new concepts in organic chemistry, and your treatment on ambient reactivity (Angew. Chem. Int. Ed. 2011, 50, 6470) is really a master piece. Over the years, it was a pleasure to collaborate with you, and our co-authored studies on the halogenmagnesium exchange (Angew. Chem. Int. Ed. 2007-2009) have really been very stimulating. I realized that we have published more than 15 manuscripts together over the years, and I have to confess that our collaboration in the frame of the DFG Collaborative Research Center SFB 749 was scientifically most productive. It is always so interesting to discuss science with you, and our fruitful collaboration is one of my most positive experiences at the LudwigMaximilians-Universität.

Dear Herbert, I know that what you appreciate most among chemists is modesty, but I would like to mention in this Editorial that your science is recognized worldwide and has been recognized by several important prizes. You are member of the German Academy of Science Leopoldina and of the Bavarian Academy of Science. I admire your scientific work, but also your exceptional energy and working power. Your kindness and scientific insight make you an ideal colleague and friend.

In the name of my colleagues, of all the contributors of this Special Issue of SYNTHESIS, I would like to wish you all the best for the future, especially a good health to you, to your wife Edith, and to your family. We wish you further success in your journey in chemistry.

Best wishes,

Paul

Prof. Paul Knochel

Ludwig-Maximilians-University, Munich

Editor-in-Chief of SYNTHESIS

knoch@cup.uni-muenchen.de 